\title{
CIGRE Session 2016
}

\section{G. Christiner}

Online publiziert am 27. Jänner 2017

(C) Springer Verlag Wien 2017

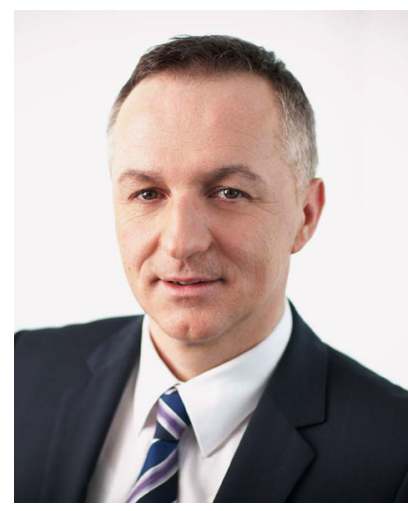

VDir. Mag. (FH) Dipl.-Ing. Gerhard Christiner
Die 46. CIGRE Session fand vom 21.-26. August 2016 in Paris statt. Mit knapp 3.300 Session-Teilnehmern aus über 90 Ländern, darunter 60 aus Österreich, sowie über 8.000 Besuchern der parallel zur Session stattfindenden Ausstellung war auch bei der diesjährigen Konferenz das Interesse an den aktuellen Entwicklungen in der Branche enorm.

Als weltweit bedeutendste Plattform ihrer Art bietet die CIGRE Session alle zwei Jahre Vertretern der Energiewirtschaft und Industrie, Elektrotechnik-Experten und Wissenschaftlern die Gelegenheit zum Erfahrungs- und Wissensaustausch sowie zur Diskussion aktueller Entwicklungen im Bereich der Energiewirtschaft.

Die Schwerpunktthemen 2016 waren unter anderem:
- Protection and Automation

- System Development and Economics

- System Environmental Performance

- Materials and Emerging Test Techniques

- Distribution Systems and Dispersed Generation

Der Titel des Eröffnungs-Panels unterstrich einmal mehr den tiefgreifenden Transformationsprozess, inmitten dessen sich die europäische Elektrizitätswirtschaft nach wie vor befindet: Big Shift in Power - Shaping the System of the Future.

In den einzelnen Arbeitsgruppen und Workshops ging es dann auch durchgängig um die Grundsatzfrage, welche Auswirkungen auf die einzelnen Arbeitsbereiche sich aus den aktuellen Systementwicklungen ableiten lassen und wo die Lösungsansätze für die aktuellen Herausforderungen liegen könnten.

Auch die 46. CIGRE Session 2016 war geprägt von spannenden und fruchtbaren Fachdiskussionen. Einen Auszug daraus finden Sie wie immer in den Ihnen hier vorliegenden Berichten.

Ich wünsche Ihnen eine spannende Lektüre!

Gerhard Christiner

Vorsitzender des Österreichischen Nationalkomitees der CIGRE
Christiner, Gerhard, Austrian Power Grid AG, Wagramer Straße 19, 1220 Wien, Österreich (E-Mail: gerhard.christiner@apg.at) 